Available online at http://docs.lib.purdue.edu/jate

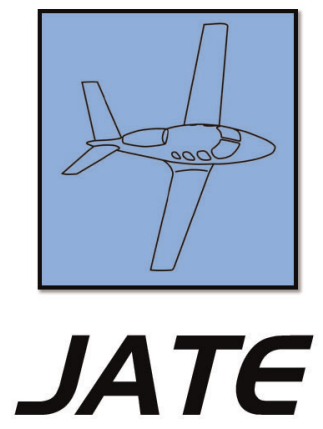

Journal of Aviation Technology and Engineering 10:1 (2021) 45-57

\title{
Fatigue and Its Management in the Aviation Industry, with Special Reference to Pilots
}

\author{
Rajee Olaganathan, Timothy B. Holt, Jackie Luedtke, and Brent D. Bowen \\ Embry-Riddle Aeronautical University
}

\begin{abstract}
Fatigue is a significant contributing factor that reduces human ability and leads to accidents and threatens the safety of aircraft and human lives. Approximately $70 \%$ of fatal accidents that occur in commercial aviation operations are due to human factors. More specifically, crew fatigue contributes to nearly 15 to $20 \%$ of the accidents (Akerstedt, 2000). These accidents and incidents are associated with pilot fatigue because of the long duty periods, disruption of circadian rhythms, and inadequate sleep that are common among both commercial and military pilots. Though fatigue is seen in all the disciplines associated with the aviation industry, this paper will discuss only pilot fatigue. Based on the literature examined, this paper first defines fatigue, examines the significance of the problem, discusses what is fatigue, its types and causes, discusses fatigue-related accidents and incidents, examines fatigue in different flight operations and its impact on the wellbeing of pilots, investigates the in-flight and pre-/post-flight countermeasures (both pharmacological and nonpharmacological methods) practiced at present, and discusses the fatigue risk management system (FRMS)—in this it defines FRMS, briefly discusses its history, describes the organizational structure of FRMS, its process, and its operation in the aviation industry, merits and demerits of FRMS, and its future applications. The paper finally concludes with some recommendations for future research/study in this discipline.
\end{abstract}

Keywords: fatigue, pilots, aircrew, napping, long-haul flights, ultra-long range, short-haul flights, FRMS

\section{Introduction}

Fatigue can be described as a feeling of exhaustion, extreme physical and mental tiredness, or lack of energy that is not relieved by rest. Fatigue is defined as "a biological drive for recuperative rest. This rest may or may not involve a period of sleep depending on the nature of the fatigue" (Williamson et al., 2011, p. 499). At the end of the nineteenth century, fatigue attracted the attention of researchers. In the early 1900s, research was carried out on the physiological aspects of sleep, circadian rhythms, sleep-wake cycles, and the effect of sleep deprivation. The impact of fatigue on performance gained focus specifically in high-risk industries after the 1950s (Noy et al., 2011).

Aviation comes under the high-risk industries, being significantly affected by fatigue especially with regard to occupational safety and effective performance (Haugh et al., 1994). Among the 70\% of fatal accidents that occur in commercial aviation nearly 15 to $20 \%$ of such accidents occurred due to crew fatigue (Akerstedt, 2000). The consequences 
of long duty hours on flight performance which was first reported in the early 1920s led to the development of the Civil Aeronautics Act of 1938 and developed aircrew duty hours and flight times (Mohler, 1966). Samel et al. (1995) reported that among all the issues, pilot fatigue is substantially the most important one due to the long duty periods, unpredictable hours of work, disruption of circadian rhythms, and lack of quality sleep. When pilots are sleep-deprived, they cannot think and react quickly; they experience memory difficulties and make mistakes that lead to errors and accidents. The negative impacts of prolonged sleeplessness and long duty periods affect crew performance, and in 1930, researchers correlated this to the rapid change in time zones (Mohler, 1966).

Bourgeois-Bougrine et al. (2003) attributed pilot fatigue during long-haul flights to the deprivation in sleep pattern and circadian rhythm related to the transition to different time zones. However, with regard to short-haul flights, it is related to high workload and sleep deprivation (Powell et al., 2007). However, irrespective of whether short-haul or long-haul flights, pilot fatigue is generally linked to night flights, jet lag, time pressure, multiple flight legs, and consecutive duty periods without sufficient recovery breaks. Similar issues were reported among corporate/executive pilots by Rosekind et al. (2000).

Among executive pilots, the primary issues for fatigue are night flights, multi-segment flights, early awakenings, and late arrivals (Rosekind et al., 2000). In addition to these factors, weather and turbulence also contribute to fatigue among pilots (Caldwell, 1997). Caldwell and Gilreath (2001) reported that lack of quality sleep caused low performance among U.S. Army helicopter pilots. Melfi and Miller (2006) noted the same problem among U.S. Air Force pilots. In 1992, the U.S. Navy fighter pilots stationed in Operation Southern Watch complained that their sleep deprivation caused performance degradations (Belland, and Bissell, 1994).

Irrespective of the type of operation, whether it is military or commercial (national or international) or cargo, pilot fatigue will continue to be a challenge in the aviation industry. The operational hours for ultra-long-range (ULR) aircraft are usually longer than those for domestic and international flights. The duty periods of the aircrew is also extended. Hence, the crew has to work during nonstandard, extended duty schedules and the ULR operations worsen the fatigue issues which already have a negative impact on performance and impair aircraft safety (Neri, 2005). Fatigue also affects the physiological wellbeing of pilots, particularly affecting the function of the central nervous system. It leads to higher incidences of stomach problems, colds, flu, cardiovascular problems, menstrual irregularities, and weight gain. Cabon et al. (1993) revealed that long-haul pilots were prone to vigilance lapses during lowworkload periods and, at times, these types of lapses could occur simultaneously in both the pilots. For example, micro-sleeps, or short involuntary moments of inattention, are likely to occur during the middle to the last segment of long haul flights (Samel et al., 1997; Wright \& McGown, 2001).

Fatigue poses a significant risk to crew members, passengers, and aircraft when it is not well managed. Caldwell and Gilreath (2002) reported that only $4 \%$ of military accidents occur due to fatigue. Yet $7.8 \%$ of U.S. Air Force mishaps (Luna, 2003), and 12.2\% of the U.S. Navy's accidents are attributed to fatigue (Ramsey and McGlohn, 1997). The National Transportation Safety Board (NTSB) has identified that approximately $20 \%$ of aviation accidents that occurred between 2001 and 2012 were due to pilot fatigue (NTSB, 2016). Thus, fatigue is a significant risk factor for occupational safety, performance effectiveness, and personal wellbeing.

These research studies provided various recommendations to mitigate crew members' fatigue. But relatively few changes occurred in aircrew scheduling and flight time limitations as the regulations vary among different countries. The knowledge gained through research studies related to the relationship among fatigue, circadian rhythms, and shiftwork was not integrated into realization (Dinges et al., 1996). Hence, the problems that occur due to pilot fatigue have increased substantially according to accident and incident statistics. An effective management strategy is essential for managing fatigue-related issues as the concern over aviation safety has tremendously increased (Dinges et al., 1996). This paper aims to study the significance of pilot fatigue with a holistic approach by reviewing scientific evidence to examine the causes and implications of fatigue in the aviation industry. It examines questions like whether the industry should be concerned about the effect of fatigue, whether there is any association among fatigue, performance, and safety, and whether there are any gaps in the knowledge in this field, and what should be the direction for future research in this discipline.

\section{Research Method}

This study is based on the published scientific literature. The five electronic databases searched for this study are Google Scholar, Science Direct, PubMed, Hunt Library of Embry Riddle Aeronautical University, and Web of Science. The search was limited to articles that were published between 1965 and 2019. The keywords used either individually or in combination for the literature search were: fatigue, sleep, napping, pilots, long haul, short haul, accidents, risk management, countermeasures. An initial screening was done to put together all the related studies depending on their objective. After a full review, the studies were filtered to remove duplication. The documents collected for this study included manuals, regulations, advisory circulars, and research reports from the industry, peer-reviewed articles published in journals, conference papers, and books. 


\section{Results}

Based on the literature examined, the data were analyzed and the findings presented in a narrative form. The paper first discusses various types of fatigue and its causes, then discusses the consequences of fatigue-related accidents and incidents, examines fatigue in different flight operations and its impact on the wellbeing of pilots, investigates the types of countermeasures practiced at present to reduce the adverse effects, briefly examines the fatigue risk management system (FRMS), and concludes by identifying research gaps and providing some recommendations for future research in this discipline.

\section{Fatigue: Its Types and Causes}

In 1973, Bader defined fatigue as a significantly reduced ability to carry out a task. Recently, in 2009, the European Aviation Safety Agency (EASA) and the International Civil Aviation Organization (ICAO, 2012) defined fatigue as a physiological state in which either mental or physical performance capability or both is considerably reduced due to the loss of sleep or due to extended wakefulness and/or physical activity that can ruin a crew member's alertness and the ability to operate an aircraft safely (EASA, 2009). Sleep-related fatigue is generally classified into two types, acute and chronic. Acute fatigue is only short term, which occurs due to an extended period of wakefulness and can be mitigated by an adequate period of sleep, while chronic fatigue occurs due to the delayed or incomplete recovery from acute fatigue or cumulative sleep inadequacy. As such, chronic fatigue is more serious than acute fatigue. Fatigue is again divided into physical and mental fatigue. Physical fatigue is the inability to continue the work effectively due to a lack of strength that usually occurs as a result of heavy exercise while mental fatigue occurs either due to a state that exists between wakefulness and sleep that includes micro-sleeps or decreased level of concentration that is not necessarily connected with sleepiness. This latter state is the main concern with regard to fatigue in aviation as it is generally associated with flight crews, and it has an implication for flight operation and poses a threat to safety (EASA, 2009).

The state of fatigue is generally influenced by different factors such as homeostatic process, circadian rhythms, sleep inertia, sleep debt, task load, and personal sleep physiology of a person. Among these factors, homeostasis is the internal drive of the body for sleep that plays a main role in maintaining the night sleep while the circadian rhythm is the brain's function that controls the diurnal peaks and troughs of different behavioral and physiological variables. But, together these two factors have an important effect on the level of alertness and situational awareness (Caldwell \& Caldwell, 2003; Dijik \& Czeisler, 1997). Sleep inertia is the grogginess sensation experienced after awakening from a deep slow-wave sleep and is considered the next greatest cause as this can extend for several minutes and have a negative impact on the performance of pilots. Caldwell and Caldwell (2003) reported that the normal sleep required is around eight hours per day but it might vary between seven and nine hours depending on the individual person. If this sleep period is affected due to shiftwork or trans-meridian time shifts, then a sleep debt will accumulate and over time it might lead to fatigue and affect the quality of operational performance. The effect of fatigue that occurs due to work-oriented task load is still complex, depends on the nature of work, its level of difficulty, training and experience of the individual person, and an organization's culture (Hart \& Staveland, 1988). At the same time, personal sleep physiology varies widely from person to person as the tolerance level to various elements that have an impact on fatigue differs significantly.

\section{Consequences of Fatigue and Related Accident and Incident Statistics}

The biological effects of fatigue will significantly degrade the operational performance of an affected person in spite of their extensive training, experience, and motivation. Based on its research, the Australian Transport Safety Board (ATSB, 2006) confirmed this negative impact. Mental fatigue affects concentration skills and thereby causes lapses in attention, difficulty in remembering by anticipating events with required actions. It also affects communication skills that results in non-communication of important information (Transport Canada, 2007). An increase in the occurrence of irritability incidences, impatience, and decreased social inhibitions were reported by transportation safety board studies (ATSB, 2006; NTSB, 2008). At times it also results in the inability to control the mood and associated behavior due to sleep deprivation.

As discussed above, fatigue is an unavoidable consequence of interrupted sleep schedules. In the case of pilots, it might result in missed radio calls, inaccurate flying, micro-sleep, and poor communication that ultimately cause the loss of situational awareness. All these factors result in accidents that cause huge losses both in terms of costs and lives. In the aviation industry, the first accident in which fatigue was reported to be the primary cause was the crash of the aircraft Kalitta International DC-8-61F at Guantanamo Bay in 1993. National aviation authorities of various countries have recorded fatigue as a prime cause of several accidents; the details of those accidents are provided in Table 1.

The trend of fatigue-related accident risks will increase in the future due to the high competition in the industry. To manage the competition there is a high likelihood that airlines would increase pilot work periods to improve productivity (ATSB, 2006). On the other hand, the sophistication of aircraft is increasing and they are capable of 
Table 1

Fatigue-related accidents/incidents

\begin{tabular}{|c|c|c|c|c|}
\hline Year & Airline & Aircraft & Location & Reference \\
\hline 1993 & Kalitta International & DC-8-61F & Guantanamo Bay & Learmont (2009) \\
\hline 1994 & Air Algerie & $737-200 \mathrm{~F}$ & Coventry, UK & Learmont (2009) \\
\hline 1997 & Korean Air & $747-300$ & Guam, Pacific Ocean & Learmont (2009) \\
\hline 1999 & American Airlines & MD-82 & Little Rock, Texas, USA & Learmont (2009) \\
\hline 2001 & Crossair & BAe146-Avro 146-RJ100 & Zurich, Switzerland & Learmont (2009) \\
\hline 2002 & AgcoCorp & Challenger 604 & Birmingham, UK & Karen (2010) \\
\hline 2004 & MK Airlines & $747-200 \mathrm{~F}$ & Halifax & Karen (2010) \\
\hline 2004 & Corporate Airlines & BAeJetstream31 & Kirksville, USA & Karen (2010) \\
\hline 2004 & 2004 Med Air & Learjet35A & San Bernadino, California, USA & Karen (2010) \\
\hline 2005 & Loganair & B-N Islander & Machrihanish, UK & Learmont (2009) \\
\hline 2006 & Comair & CRJ100 & Lexington, Kentucky, USA & Karen (2010) \\
\hline 2007 & Cathay Pacific & $747 \mathrm{~F}$ & Stockholm Arlanda, Sweden & Learmont (2009) \\
\hline 2007 & One-Two-Go & MD-82 & Phuket, Thailand & Karen (2010) \\
\hline 2009 & ColganDash & 8-Q400 & Buffalo, New York, USA & Learmont (2009) \\
\hline 2009 & Emirates & A $340-500$ & Melbourne, Australia & Karen (2010) \\
\hline 2010 & Air India Express & $737-800$ & Mangalore, India & Ministry of Civil Aviation (2010) \\
\hline 2011 & Air Canada & $767-300$ & North Atlantic & $\begin{array}{l}\text { Transportation Safety Board } \\
\text { of Canada (2011) }\end{array}$ \\
\hline 2013 & $\begin{array}{c}\text { Asiana Flight } 214, \\
\text { Korean airliner }\end{array}$ & 777 & San Francisco, California, USA & NTSB (2014) \\
\hline 2013 & UPS & A300-600 & Birmingham-Shuttlesworth & Reuters (2013) \\
\hline 2016 & FlyDubai jet & $737-800$ & Rostov-on-Don, Russia & BBC News (2016) \\
\hline
\end{tabular}

flying for longer periods without layovers (ultra-range flights) and this, in turn, increases the demands imposed on the flight crew.

\section{Fatigue in Varied Flight Operations and Its Impact on Pilots}

In airline operations, whether it is a short-haul flight (SHF), long-haul flight (LHF), or ultra-range flight (URF), the main problem is the fatigue among pilots. Often it occurs as a result of irregular duty schedules and the difficulties in maintaining normal sleep patterns during LHF or URF. Goode (2003) reported that a positive relationship exists between the duty hours and the probability of accidents. It was identified that different types of flight operations have various fatigue factors. Among those, flight fatigue alone might be an important factor in aviation accidents even though it is difficult to investigate and prove whether fatigue is the prime cause or not (Co et al., 1999; Yen et al., 2005).

Yen et al. (2009) reported that in the case of regional flights with times ranging from two to six hours, the factors that result in fatigue are different among the crew members. Crews serving SHFs, flights with times less than two hours, experience fatigue due to early departures, late arrivals, and multiple takeoffs and landings that are workload-demanding (Yen et al., 2009). A cramped cockpit environment and the age of the crew members are negative factors that contribute to fatigue. Moreover, SHFs are carried out by two pilots and, hence, there is no opportunity for rest in flight and this can cause more fatigue levels (Eriksen et al., 2006). Compared with LHFs, less research has been carried out on the factors that contribute to fatigue in SHFs. The study carried out by Powell et al. (2007) on Air New Zealand Boeing 737 operations (SHFs) proved that the number of sectors flown and the duty length are significant factors that influenced the fatigue in SHF pilots. That study also indicated that the time of day had low influence on fatigue which increased subsequently during the later time of the day. Fatigue was also higher when duties originated from an airport where pilots need to be positioned the night before and spend the night in a hotel. This finding was inconsistent with the results of other studies (Civil Aviation Authority, 2005; Gander et al., 1994; Nicholson et al., 1986a). Bourgeois-Bougrine et al.'s (2003) study on fatigue among long-haul and short-haul pilots operating 739 aircraft confirmed that in addition to multiple legs per day and the duty period, time constraints also have a crucial impact on fatigue among pilots operating SHFs. In SHFs mistakes are related to time pressure and the increased workload during short multi-leg flights and supervising and monitoring activities become difficult (Bourgeois-Bougrine et al., 2003; Lyman \& Orlady, 1981).

Crew members serving oceanic LHFs, i.e., flights with times exceeding six hours, experience problems such as loss of sleep and disruption of circadian rhythms. This is associated with the quality of sleep they have both on board and at home and that is considered as a prominent factor that affects the fatigue level (Yen et al., 2009). Samel et al. (1995) reported on the irregular schedules of LHF pilots which often include early departures, extended duty periods, night work, and/or time zone changes. Petrilli et al. (2006) reported that LHF pilots experienced higher fatigue levels due to the lack of quality sleep, continuous insomnia, and 
disruption of circadian rhythms which significantly reduced the response time from the beginning to the end of the flight. This ultimately decreased awareness and pilot alertness, increasing dangers that resulted from less response. Due to this, some pilots become stressed taking unnecessary risks like deliberately flying into an area which is a risk, doing things due to impulsion, exhibiting a macho attitude and antiauthority (Drury et al., 2012; Hardaway \& Gregory, 2005). Petrie et al. (2004) stated that approximately $66 \%$ of LHF pilots experienced fatigue at least once a week and $96 \%$ of them reported that it affected their usual social activities. There was a significant correlation between the duration of the flight and the frequency of accidents and $20 \%$ of the accidents were due to human factors especially when pilots had a long duty period of more than 10 hours (Goode, 2003). Apart from duty-related factors, some researchers have found that certain environmental factors such as glass cockpits and automation in the flight deck also increase sleepiness and risk of aircraft accidents.

Rosekind et al. (2000) and Samel et al. (1997) through their studies confirmed that the advances achieved on the technological side have made it possible to automate most of the activities on the flight deck; this has considerably reduced the cognitive workload of both the pilots and the crew members. Neri et al. (2002) stated that the "glass cockpits" and the head-up display systems show the data onto the cockpit window; due to this advantage pilots are capable of flying aircraft without looking down inside the cockpit to check the altitude, airspeed, etc. Some head-up display systems have a synthetic vision, i.e., they can even project the view of the proposed runway even when it is not actually visible. This has improved human capabilities with regard to the improvement in track and glide path maintenance approach, improved landing precision, reduced the visibility required for takeoff and landing, and has increased situational awareness (Crawford \& Neal, 2009; Homan, 2013). This technological advancement had replaced the traditional analog displays in modern aircraft and working in this type of boring environment might lead to deterioration in vigilance, and increase in sleepiness among pilots.

Roach et al. (2012) confirmed that fatigue might be worsened by other factors such as dim lighting on the flight deck and absence of feedback through analog displays. These issues might be worsened by physiological stressors such as hypoxemia and/or hypoxia. Hypoxia is common among pilots flying at 8000 feet above sea level and the symptoms are similar to the effects of fatigue such as decreased vigilance and reduced situational awareness (Civil Aviation Subcommittee, 2008). In addition to the fatigue issues among pilots, some detrimental physiological and psychological effects have also been observed. All these effects together affect the general health and wellbeing of pilots (Eriksen et al., 2006). Leproult et al. (1997) reported an increase in the level of cortisol, the stress hormone, after sleep deprivation; Spiegel et al. (1999) observed similar results after sleep restriction for six consecutive nights and repeated sleep loss increased the risk for diabetes; Meerlo et al. (2008) reported that these effects increase cardiovascular complications, slow metabolism, and increase the rate of psychiatric disorders; and Venkatraman et al. (2007) stated that these factors increased risk-taking behavior.

\section{Fatigue Countermeasures}

As discussed in the previous session, fatigue poses a severe risk in terms of both a safety perspective and the wellbeing of crew members. Gregory et al. (2010) stated that nothing can compensate for the loss of sleep and it is a physiological necessity. In some circumstances, such as LHFs and URFs, long sleep duration may not be possible. In these situations, to overcome fatigue-related risks, several countermeasures such as in-flight countermeasures and/or pre-/post-flight countermeasures have been adopted in the aviation industry; these are discussed briefly in the following.

\section{In-flight countermeasures}

(i) Cockpit napping. This refers to napping on the flight deck. Goldsmith (1998) stated that Air Canada, Air New Zealand, British Airways, Emirates, Finnair, Lufthansa, Swissair, and Qantas had authorized cockpit napping. Co et al. (1999) conducted a study on regional airline operators which reported that $56 \%$ of flight crews confirmed that they had been on a flight in which arrangements were made for one pilot to sleep in the seat during a segment. The commercial pilots of the USA were utilizing this cockpit napping strategy. About $39 \%$ of the corporate pilots confirmed that they were utilizing this strategy (Rosekind et al., 2000).

(ii) Bunk sleep. According to the Flight Safety Foundation (2005), for LHFs and URFs the most significant countermeasure implemented at present to minimize the impact of fatigue is bunk sleeping. This approach is feasible to address the issues related to sleep loss that is associated with night duties, prolonged wakefulness, and crossing multiple times. Van Dongen and Dinges (2005) suggested that scheduling of bunk sleeping periods is quite challenging as it has to be in accordance with operational demands to provide optimum rest periods to all the crew members to ensure flight safety. A study of NASA carried out by Rosekind et al. (2000) showed that environmental factors such as noise, lighting, and temperature interfere with the quality of bunk sleep which can be avoided by the better design of 
bunk facilities. Pilots of both LHFs and URFs specified that more private sleeping quarters with comfortable bedding will promote the quality/ quantity of sleep.

(iii) Activity breaks. Short breaks from routine work such as disengagement with the flying task, change in posture, increased social interaction, and mild physical activity play a significant role in reducing the monotony of cockpit work environments and increase alertness level temporarily but this depends on the type of break and the activities that are allowed during the break. Caldwell and Caldwell (2003) recommended shorter breaks (10 minutes hourly) rather than long breaks which are infrequent.

(iv) Cockpit lighting. This refers to the increased exposure to available flight deck lighting. Cajochen et al. (2000) stated that this is a potential counter measure at night. Their study confirmed the individual alertness of crew members increased with the light levels in the room. Cajochen (2007) carried out another study that proved that lights of short wavelength have the greatest alerting effect that is independent of the time of day. Due to this fact, it is possible to improve alertness and performance of crew members who are affected by sleep deprivation by utilizing light during the daytime. Especially at night, the lighting level of the flight deck helps to temporarily boost the alertness and performance level of the crew.

(v) In-flight rostering. This refers to the scheduling of flight crews on the flight deck to allotted positions so that other crew members can be freed from their duties for acquiring bunk sleep. This countermeasure directly depends on the number of pilots assigned to the flight and has to be determined during the scheduling process in advance, crew members should be educated/ informed about the rostering approach, and they should adhere to the plan during the flight—only then will it be an effective and efficient approach (Bonnet, 2005). In-flight rostering actually plays a significant role in minimizing the extended hours of wakefulness and reduces the impact of fatigue by ensuring that at least one crewmember is always rested. During the critical phases of the flight, this approach helps to utilize the ability of the crewmembers who are well rested (Bonnet, 2005).

\section{Pre-/post-flight countermeasures}

There are two major approaches to pre-/post-flight countermeasures: the non-pharmacological approach, which involves improving sleep/alertness without using medications; and the pharmacological approach, which involves the use of medicines.

\section{(i) Non-pharmacological approach}

This approach includes five different methods, namely circadian adjustment, napping, healthy sleep practices, exercise, and nutrition. These methods are discussed below briefly.

Circadian adjustment. Reid and Burgess (2005) stated that the circadian clock within the body cannot adapt instantly according to changes in environmental cues. The adoption and adjustment depend on the exposure to time cues such as light/dark cycle, the number of time zones crossed, and travel direction whether westward or eastward. This adjustment is usually faster after traveling in the westward than the eastward direction (Sack et al., 2007). Atkinson et al. (2007) found that aircrew fatigue that occurs due to circadian disruption is due to the partial alleviation with hypnotics. Moreover, they stated that adjusting to a new time zone or work schedule depends on certain strategies such as having meals and sleep at appropriate times, avoiding heavy meals at night, maximizing exposure to sunlight during the morning hours, and reducing it during the evening hours. The study also stated that during the first few days, pilots use authorized sleep medications to sleep at night and take caffeine during the day to enhance alertness (Atkinson et al., 2007). Sack et al. (2007) suggested an alternative tactic for resynchronizing the circadian rhythms after a change of schedules.

Napping. There are different types of naps such as replacement naps, taken when one is sleep-deprived; appetitive naps, taken to improve performance; and prophylactic naps, taken in preparation of sleep deprivation. Among these three nap types, prophylactic naps play a significant role in improving performance (Dinges, 1992). While implementing the napping strategy the nap length and timing are the important factors to be considered. A study carried out by Bonnet (1991) proved that prophylactic naps before a night shift resulted in maximum performance. Later studies also proved that prophylactic naps were effective in enhancing the quality of operational performance (Brooks \& Lack, 2006; Driskell \& Mullen, 2005). Such studies also indicated that performance level was directly proportional to the nap length. It was also noted that regardless of the nap length, the performance level decreased when the post-nap interval increased.

Healthy sleep practices. Generally, people require eight hours of sleep per day (Wehr et al., 1993). Sufficient quantity and quality of sleep are essential for maintaining the best possible mental alertness. Bonnet and Arand (2003) reported that sleep fragmentation reduces memory, vigilance, reactive time, and even the mood. Hence, quality sleep is very important. The common recommended strategies for getting quality sleep are: waking up and going to bed at the same time, a consistent bedtime routine, keeping the place quiet, cool, dark, and comfortable, and avoiding caffeine drinks in the evening that helps to optimize sleep opportunity. 
Exercise and nutrition. Exercise stimulates the level of alertness within a short time by increasing physiological arousal. But the timing and the level of exercise are important factors when considering it as a fatigue countermeasure. Morin (2006) suggested that the quality and quantity of sleep improved especially in the case of those who exercise on a regular basis, but exercise also has a negative impact if it is done too close to bedtime. Shiota et al. (1996) carried out research on airline crew members who flew between Los Angeles and Tokyo. Their data proved that moderate to heavy exercise done before the flight duty at both cities played a significant role for pilots in adapting to the local time zone. All of this research proved that exercise helps a lot in adjusting to a new time zone by facilitating a delay either in wake up or sleep cycle, especially during westbound travel.

Maintaining good nutrition is important for healthy living. Neumann and Jacobs (1992) stated that any difference in regular nutrition might have an impact on sleep pattern and there might be mild effects due to diet supplements. The study conducted by Zammit et al. (1995) confirmed that a carbohydrate lunch will increase the length of a siesta, and bedtime was found to be associated with decreased wakefulness and reduced stage 1 and 4 sleep with increased rapid eye movement. They also found that the effects of a carbohydrate meal depend on the time of consumption during the day, gender, and age. Afaghi et al. (2007) observed that sleep latency decreased by $50 \%$ with a $90 \%$ carbohydrate meal with a high glycemic index. At the same time, a low glycemic index carbohydrate meal delayed the start of drowsiness. The comparative study carried out between high-fat, low-carbohydrate meal and low-fat, high-carbohydrate one by Wells et al. (1997) showed that the higher concentrations of cholecystokinin after high-fat, low-carbohydrate meal increased the feelings of sleepiness and fatigue. Skipping meals also triggered the disruption of sleep and increased fatigue. Low blood glucose (hypoglycemia) can lead to reduced cognitive performance. All the studies have emphasized that aircrew should have a balanced meal at regular intervals in order to maintain general health and recommend them avoiding large meals before bedtime. In general, attempting to control sleep and alertness by manipulating dietary constituents is not advised (Zammit et al., 1995).

\section{(ii) Pharmacological approach or hypnotics}

Even if efforts are made to ensure a good sleep, in operational contexts it is quite often difficult to get that due to one or more of the following reasons: (1) the sleep environment may be too noisy, hot, or uncomfortable; (2) incompatibility of the individual to sleep, i.e., if they are too excited or anxious; and (3) the opportunity to sleep occurs at a time which is not conducive to rapid sleep onset and/or sufficient sleep maintenance. This might be due to jet lag, change in work shift, or attempting to sleep at places and times that are different from habitual bedtime or at the second circadian dip in the afternoon. The U.S. Air Force and Army have approved the limited use of temazepam, zolpidem, and zaleplon for this type of situation (Nicholson et al., 1986b). These drugs help to optimize the sleep quality of crew in circumstances where sleep is difficult. The choice of the drug depends on the time of the day, the length of the sleep period, the half-life of the compound, etc. Among these hypnotic drugs, for prolonged hypnotic effect, 15 to $30 \mathrm{mg}$ of temazepam has been recommended for military aircrew in Great Britain since the 1980s if the sleep period is not to be reduced unexpectedly (Nicholson et al., 1986b). To promote short to moderate sleep durations, i.e., for four to seven hours of sleep, zolpidem is the best choice compared to temazepam (Gillberg, 1984). While for short naps of one- to two-hour duration, 5 to $10 \mathrm{mg}$ of zaleplon is the best choice especially for initiating an early sleep onset in personnel who are trying to ensure sufficient sleep prior to a very early start time the next morning (Gillberg, 1995). Whenever there is a problem with sleep maintenance or initiating sleep, these compounds can be used only in operational contexts because all these medications have both benefits and risks associated with them. Before finalizing the compound, it has to be considered by the physician and the individual pilot. It is important to remember that a hypnotic drug of any kind cannot be used if the crewmember is likely to be called back to duty earlier than the anticipated duty period (Stone \& Turner, 1997). In short, it is better to adopt healthy sleep practices.

\section{Fatigue Risk Management Systems}

From an aircrew member perspective, all the countermeasures discussed above are employed to offset fatigue. Mainly they are lifestyle-type choices that reduce stress through adopting healthy practices regularly. While in order to manage sleep patterns and disruption of circadian rhythms, LHF and URF pilots and crew members should be aware of their own physiological traits and have a good knowledge of the physiology of sleep. In commercial aviation, an airline is bound by regulation to adopt practices and procedures that prevent the onset of fatigue. The crew rest period and their flight and duty time for commercial aviation are regulated by the Federal Aviation Administration (FAA) under the Code of Federal Regulations (CFRs). The FAA has imposed strict limitations on minimum crew rest periods. "The current flight time limits and rest requirements for part 121 and 135 crewmembers are covered in 14 CFR part 121 , subparts $\mathrm{P}, \mathrm{Q}, \mathrm{R}$ and $\mathrm{S}$ (domestic, flag, and supplemental operations) and 14 CFR part 135, subpart F (on-demand and commuter operations)" (Kirkland, 2008). In 2001, the FAA enforced the 16-hour duty day as codified in 14 CFR 121.471. The Advisory Circular AC121-31 (flight crew sleeping quarters and rest facilities) addresses the onboard sleeping facilities for crew 
members and AC120-51E deals with crew resource management training and establishes the importance of curriculums that address fatigue mitigation and fatigue's effect on performance (Kirkland, 2008). OpSpec A332 addresses the issues related to ULR operations based on both scientific and operational perspectives.

The traditional method of fatigue countermeasures adopted is generally in compliance with an approved flight time limitation (FTL) scheme. These FTL schemes limit the hours of work and thereby prevent fatigue; these limits date back to the 1950s when the difference between mental and physical fatigue was not valued much. Recently, based on scientific research, the aviation industry is adopting a more flexible, multifaceted, and holistic approach in tackling fatigue issues with respect to organizational, environmental, and physiological factors. This approach is both proactive and reactive which is referred to as FRMS. The FAA has enforced it as an alternative approach to traditional prescriptive methods (Akerstedt, 2000).

The ICAO has defined FRMS as "A data-driven means of continuously monitoring and managing fatigue-related safety risks, based upon scientific principles and knowledge as well as operational experience that aims to ensure relevant personnel are performing at adequate levels of alertness" (ICAO, 2012). It includes a good rostering practice, clear policies and procedures for the workplace, effective monitoring of safety-related outcomes, and active involvement from management (ATSB, 2006). According to Virgin Atlantic Airways (2008), FRMS is a risk reduction process that involves the following: (1) identification of a hazard that causes fatigue, (2) evaluating its severity and likelihood of its occurrence, (3) assessment of the risk it poses, and (4) implementation of mitigation measures to reduce the risk. This includes developing mitigating strategies and schedule adjustments that occur as a collaborative management process between stakeholders. Thus, shared responsibility among stakeholders is an important aspect of FRMS.

According to the FAA (2013), the defense layers implemented to prevent fatigue and the related errors in the aviation industry are: adjusting the scheduling rules with regard to flight duty schedule and the additional tasks to provide recovery sleep opportunities to crew members, maximizing the use of existing sleep opportunities to reduce cumulative fatigue (this is mainly crewmembers' responsibility), implementing error detection and corrective processes that can prevent operational consequences of fatigue, and conducting comprehensive and objective accident, incident, and error analyses that can help to determine where fatigue can be a potential contributor. These data can be utilized to avoid such circumstances in future.

The organizational structure of FRMS is illustrated in Figure 1. The Fatigue Management Steering Committee plays a crucial role in all FRMS processes. The FRMS process involves four main steps, namely assessment of current conditions, modeling and analysis of fatigue risk, mitigation of fatigue risk, and assessment and feedback. These steps repeat continuously, decreasing fatigue-related risk and improving the performance level (Figure 2).

FRMS was first introduced by the Civil Aviation Authority of New Zealand in the aviation industry in 1995 as an "alternative compliance scheme" (Civil Aviation Safety Authority [CASA], 2004). In 2001, the CASA introduced FRMS in the Australian aviation industry. Due to the

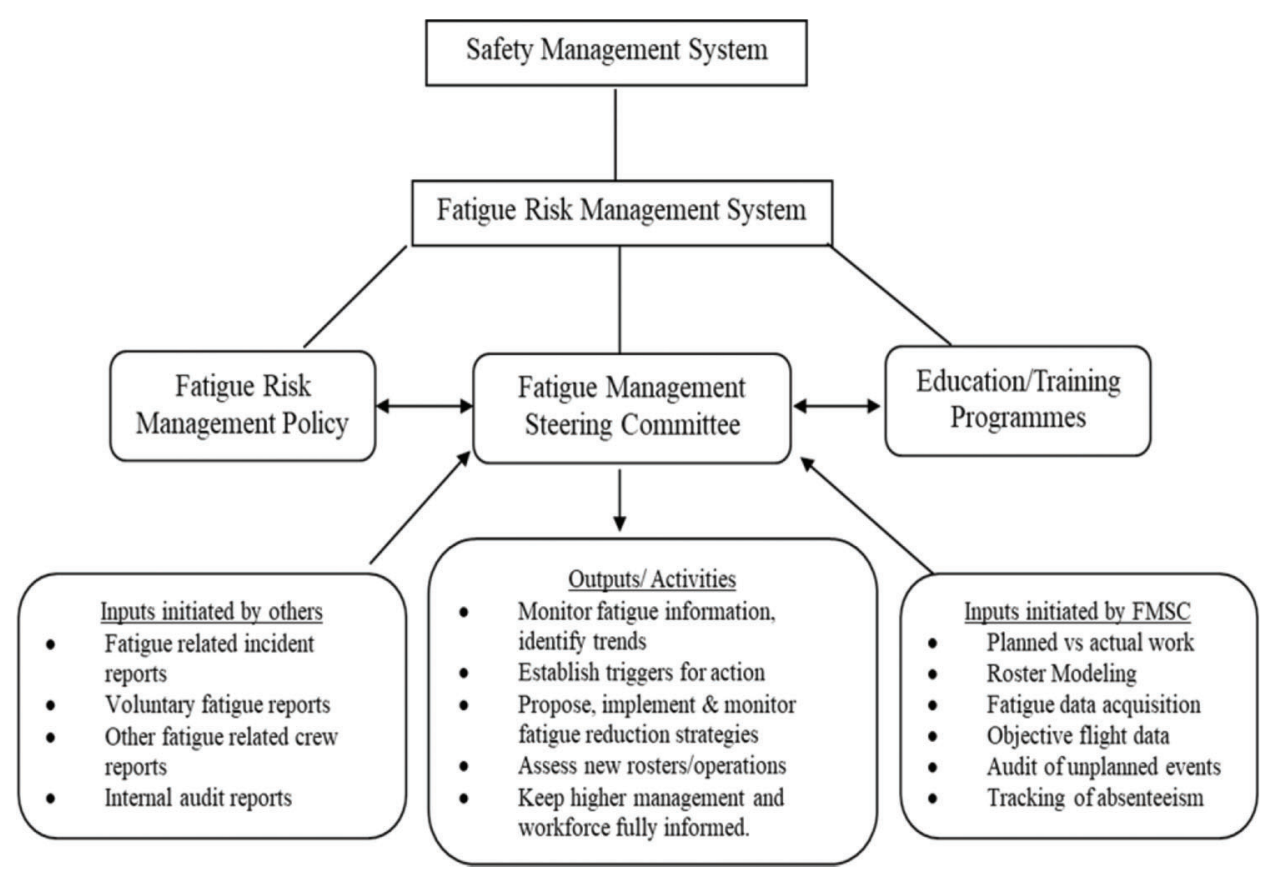

Figure 1. FRMS organizational chart. Adapted from "Fatigue risk management system help ensure crew alertness performance" by ULR Crew Alertness Steering Committee, 2005, Flight Safety Digest, 24(8-9), pp. 16-19. Copyright 2005 by the Safety Foundation. 


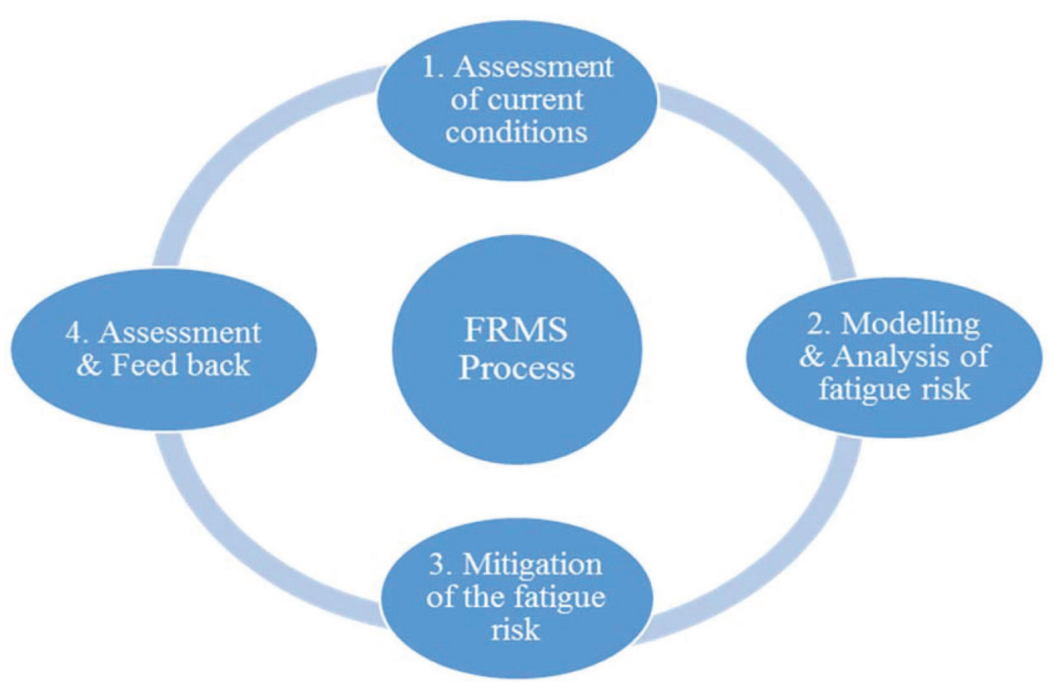

Figure 2. FRMS process. Adapted from "Fatigue risk management systems." Advisory Circular dated: 5/6/13. AC no. 120-103A for Aviation Safety, p. 10. Copyright 2013 by the FAA.

geographical remoteness and the demand in its aviation industry, it was realized that the traditional FTL schemes were not sufficient to regulate all the aviation-related activities. ULR services were introduced with the arrival of Airbus A340-500. Singapore Airlines introduced FRMS in 2003 when it started the ULR service of 16 hours and more (nonstop flights) between Singapore and Los Angeles, USA and New York, USA. Singapore Airlines was allowed to operate ULR flights due to the scientific recommendations that were based on bio-mathematical modeling. ULR flights were introduced between Dubai and Sydney as well as Dubai and New York, USA by the Emirates airline. Based on the FRMS principles, the procedures were drafted for these scheduled flights and now are accepted worldwide for LHFs also. With regard to SHFs which are dominated by low-cost carriers, in 2005 EasyJet was the first airline approved to operate with a new crew roster pattern which was based on FRMS principles. This roster allowed a sequence of 5 early starts, 2 days off, 5 late starts, and 4 days off in place of the previous cycle of 3 early starts, 3 late starts, and 3 days off (www.skybrary.aero, 2017). Fourie et al. (2010) reported that DHL Air and Jetairfly (TUI) have started their own FRMS.

\section{Research Gaps and Future Research Direction}

The extensive review of literature in this study helped to identify the gaps in fatigue management in the aviation industry. The gaps are classified into different dimensions like individualistic approach to fatigue management, organizational or operational measures in fatigue management, impact of fatigue on safety and health, application of hybrid approaches for fatigue management, and the role of technology in FRMS. A few potential areas of research in these dimensions are briefly listed below.
The individualistic approach to fatigue management is mainly focused at the individual pilot level. The future research in this dimension should aim at quantifying the level of fatigue, and assessing the role of genetics in shiftwork tolerance. Other topics should include identifying differences in fatigue response among pilots like finding any potential relationship between ethnic, demographic, and cultural differences in the way they respond to fatigue. Studies can also be conducted to check if improving the scheduling process to different fatigue levels helps to enhance safety, and how to enhance the voluntary selfreporting of fatigue by crew members (Caldwell et al., 2009; Flynn-Evans et al., 2019; Holmes et al., 2012; Noy et al., 2011). Further research can also be initiated at the organizational level or study operational measures in fatigue management. Also the efficacy of in-flight napping among long-haul pilots can be explored, a fatigue scoring system can be developed, an anonymous peer-to-peer investigation can be performed to assess fatigue management, and bio-mathematical modeling can be developed to measure the performance of pilots. Studies can also focus on the robustness of sleep/wakeup times for crew members as these times are not necessarily rigid in real practice as assumed (Dawson et al., 2017b; Honn et al., 2016; Y1ld1z et al., 2017).

For the impact of fatigue on safety and health dimension, future research is recommended to examine the consequences of shiftwork on health, investigate how the feedback from performance evaluation might affect emotional activity in crews, and how communicating between different time zones affects the circadian rhythm of ULR pilots, and the long-term effect of the utilization of psychostimulants on the cognitive ability of crew members can be evaluated (Drury et al., 2012; Flynn-Evans et al., 2019; Noy et al., 2011; Williamson et al., 2011). 
Under the application of hybrid approaches for fatigue management category, researchers could determine how fatigue detection technologies and bio-mathematical scheduling tools can be incorporated together to better manage fatigue. Interdisciplinary research could be carried out by experts in bio-mathematical tool development, fatigue device manufacturers, academics, pilots, and industry regulators in a collaborative way to improve mitigation measures for fatigue management in the aviation industry (Dawson et al., 2017a; Reis et al., 2016).

In evaluating the role of technology in FRMS, it is recommended for the industry to design better devices to detect fatigue for duty and real-time fatigue assessment. The most commonly used devices are Actiwatches (detect movement) and Actilumes (detect light). These two devices help to record when sleep is likely to occur. Two other devices used widely in the industry are the palm pilot computer test and psychomotor vigilance task. These devices help to detect the alertness level of crew members. If airlines were to make an effort to combine the mini biorhythm and the Actiwatch and have a complete objective recording of both the sleep profile and circadian rhythms of crew members, then that would eventually play a significant role in ensuring safety. It would also provide a thorough database that would contribute to future research in fatigue modeling studies. This type of FRMS application will help to assess crew members' individual tolerance to fatigue and provide information to rostering teams in allocation of trips based on the physiological routine of crew members (Caldwell et al., 2009; Deveci \& Demirel, 2018; Noy et al., 2011).

\section{Conclusion}

Fatigue is a critical problem that has damaging effects not only on the mental and physical wellbeing of an individual but also affects the quality of the performance level of humans. This occurs due to poor sleep quality or loss of sleep. Some of the measures of performance such as the level of alertness, reaction time, decision making, and cognitive processing are of particular concern in the aviation industry. The visual neglect of the central and peripheral visual fields of awareness by pilots and their increased susceptibility to stress and confusion also are major issues in airline safety. These negative impacts of fatigue affect a pilot's ability to identify a problem on time and to take the relevant corrective measure and affect the ability of pilots in implementing the right solution.

In the past, the aviation industry tried to manage fatigue issues by implementing FTLs, which was the industry best practice and was not based on any scientific research. FRMS is a holistic approach that is based on scientific research with data obtained from the industry. But it should also go beyond written regulations into more social and cultural depths.
Currently, all of the existing fatigue prediction models only predict fatigue as a point value. Thus, none of them adequately detects the probable variability in fatigue scores. One would expect to observe in a given population wide differences in sleep-wake behavior for a given shiftwork pattern. This limitation affects the way fatigue models are perceived and interpreted in real-life settings. Therefore, future research should focus on developing multicomponent fatigue management systems incorporating fatigue monitors, fitness-for-duty tests, etc. This integrated approach will give a clear picture of crew members' current and future state of fatigue and performance capacity.

Fatigue is inevitable among pilots due to the nature of their work. So, it is crucial that science-based fatigue countermeasures are included like optimization of work schedules, monitoring of sleep and fatigue, and implementing in-flight mitigation policies. This should be available to minimize the devastating consequences of fatigue. This study has identified various research needs and based on those requirements the industry needs strong research designs to objectively measure the effects of various levels of acute and chronic sleep loss, sleep inertia, and circadian disruption on operational performance and safety. It is also essential to accurately measure sleep patterns, work and circadian influences, and new intervention methods to reduce fatigue-related exposures.

\section{References}

Afaghi, A., O'Connor, H., \& Chow, C. M. (2007). High-glycemic-index carbohydrate meals shorten sleep onset. The American Journal of Clinical Nutrition, 85(2), 426-430. https://doi.org/10.1093/ajcn/85.2. 426

Akerstedt, T. (2000). Consensus statement: fatigue and accidents in transport operations. Journal of Sleep Research, 9(4), 395. https://doi. org/10.1046/j.1365-2869.2000.00228.x

Australian Transport Safety Board. (2006). Fatigue Management in the New Zealand Aviation Industry, ATSB Research and Analysis Report (B2004/0048), April 2006. Retrieved from https://www.atsb.gov.au/ media/32736/grant_20040048.pdf

Atkinson, G., Edwards, B., Reilly, T., \& Waterhouse, J. (2007). Exercise as a synchroniser of human circadian rhythms: An update and discussion of the methodological problems. European Journal of Applied Physiology, 99(4), 331-341. https://doi.org/10.1007/s00421-0060361-z

BBC News. (2016). FlyDubai crash pilot "was due to leave job over fatigue" by Stephen Fottrell, March24, 2016. Retrieved from https:// www.bbc.com/news/world-europe-35855678

Belland, K. M., \& Bissell, C. (1994). A subjective study of fatigue during navy flight operations over southern Iraq: Operation Southern Watch. Aviation, Space and Environmental Medicine, 65(6), 557-561. Retrieved from https://tinyurl.com/yjaccbe6

Bonnet, M. H. (1991). The effect of varying prophylactic naps on performance, alertness and mood throughout a 52-hour continuous operation. Sleep, 14(4), 307-315. https://doi.org/10.1093/sleep/14.4. 307

Bonnet, M. H. (2005). Acute sleep deprivation. In Kryger, M. A., Roth, T., Dement W. C. (Eds.), Principles and practice of sleep medicine (pp. 51-66). Philadelphia, PA: Elsevier Saunders. 
Bonnet, M. H., \& Arand, D. L. (2003). Clinical effects of sleep fragmentation versus sleep deprivation. Sleep Medicine Reviews, 7(4), 297-310. https://doi.org/10.1053/smrv.2001.0245

Bourgeois-Bougrine, S., Carbon, P., Gounelle, C., Mollard, R., \& Coblentz, A. (2003). Perceived fatigue for short- and long-haul flights: A survey of 739 airline pilots. Aviation, Space, and Environmental Medicine, 74(10), 1072-1077. Retrieved from https://tinyurl.com/ yz32enwo

Brooks, A., \& Lack, L. (2006). A brief afternoon nap following nocturnal sleep restriction: Which nap duration is most recuperative? Sleep, 29(6), 831-840. https://doi.org/10.1093/sleep/29.6.831

Cabon, P., Coblentz, A., Mollard, R., \& Fouillot, J. P. (1993). Human vigilance in railway and long-haul flight operation. Ergonomics, 36(9), 1019-1033. https://doi.org/10.1080/00140139308967974

Cajochen, C. (2007). Alerting effects of light. Sleep Medicine Reviews, 11(6), 453-464. https://doi.org/10.1016/j.smrv.2007.07.009

Cajochen, C., Zeitzer, J. M., Czeisler, C. A., \& Dijk, D. J. (2000). Doseresponse relationship for light intensity and ocular and electroencephalographic correlates of human alertness. Behavioural Brain Research, 115(1), 75-83. https://doi.org/10.1016/s0166-4328(00)00236-9

Caldwell, J. A. (1997). Fatigue in the aviation environment: An overview of the causes and effects as well as recommended countermeasures. Aviation, Space and Environmental Medicine, 68(10), 932-938. Retrieved from https://tinyurl.com/yjrzbsyc

Caldwell, J. A., \& Gilreath, S. R. (2002). A survey of aircrew fatigue in a sample of U.S. Army aviation personnel. Aviation, Space, and Environmental Medicine, 73(5), 472-480. Retrieved from https:// tinyurl.com/yhfrz8o7

Caldwell, J. A., \& Caldwell, J. L. (2003). Fatigue in Aviation; a Guide to Staying Awake at the Stick. Ashgate Publishing, Aldershot.

Caldwell, J. A., Mallis, M. M., Caldwell, J. L., Paul, M. A., Miller, J. C., Neri, D. F., \& Aerospace Medical Association Fatigue Countermeasures Subcommittee of the Aerospace Human Factors Committee. (2009). Fatigue countermeasures in aviation. Aviation, Space, and Environmental Medicine, 80(1), 29-59. https://doi.org/10.3357/asem. 2435.2009

Caldwell, J. L., \& Gilreath, S. R. (2001). Work and sleep hours of U.S. Army aviation personnel working reverse cycle. Military Medicine, 166(2), 159-166. Retrieved from https://tinyurl.com/yjyhjz46

Civil Aviation Authority. (2005). Aircrew fatigue: a review of research undertaken on behalf of the UK Civil Aviation Authority. CAA Paper 2005/04. Norwich, UK: Stationery Office. Retrieved from https://www. skybrary.aero/bookshelf/books/222.pdf

Civil Aviation Safety Authority of Australia. (2004). Fatigue management-Suggested alternatives to prescribed flight and duty times. Discussion Paper DP 04040S, August 2004. Retrieved from https:// www.casa.gov.au/file/144036/download?token=wX_MGUWp

Civil Aviation Subcommittee, Aviation Safety Committee, \& Aerospace Medical Association. (2008). Cabin cruising altitudes for regular transport aircraft. Aviation, Space, and Environmental Medicine, 79(4), 433-439. https://doi.org/10.3357/ASEM.2272.2008

Co, E. L., Gregory, K. B., Johnson, J. M., \& Rosekind, M. R. (1999). Crew factors in flight operations XI: A survey of fatigue factors in regional airline operations. Report no. NASA/TM-1999-208799. Moffett Field, CA: NASA Ames Research Center. Retrieved from https://ntrs.nasa.gov/citations/20000032967

Crawford, J., \& Neal, A. (2009). A review of the perceptual and cognitive issues associated with the use of head-up displays in commercial aviation. International Journal of Aviation Psychology, 16(1), 1-19. https://doi.org/10.1207/s15327108ijap1601_1

Dawson, D., Cleggett, C., Thompson, K., \& Thomas, M. J. W. (2017a). Fatigue proofing: The role of protective behaviours in mediating fatigue-related risk in a defence aviation environment. Accident Analysis and Prevention, 99(Pt B), 465-468. https://doi.org/10.1016/ j.aap.2015.10.011
Dawson, D., Darwent, D., \& Roach, G. D. (2017b). How should a biomathematical model be used within a fatigue risk management system to determine whether or not a working time arrangement is safe? Accident Analysis and Prevention, 99(Pt B), 469-473. https://doi.org/ 10.1016/j.aap.2015.11.032

Deveci, M., \& Demirel, N. C. (2018). Evolutionary algorithms for solving the airline crew pairing problem. Computational Industrial. Engineering, 115, 389-406. https://doi.org/10.1016/j.cie.2017.11.022

Dijik, D.-J., \& Czeisler, C. A. (1997). Contribution of the circadian pacemaker and the sleep homeostat to sleep propensity, sleep structure, electroencephalographic slow waves and sleep spindle activity in humans. Journal of Neuroscience, 15(5), 3526-3538. https://doi.org/ 10.1523/JNEUROSCI.15-05-03526.1995

Dinges, D. F. (1992). Adult napping and its effects on ability to function. In Stampi C. (Ed.), Why we nap (pp.118-132). Boston, MA: Birkhauser.

Dinges, D. F., Graeber, R. C., Rosekind, M. R., Samel, A., \& Wegmann, H. M. (1996). Principles and guidelines for duty and rest scheduling in commercial aviation. Report no. 110404. Moffett Field, CA: NASA Ames Research Center. Retrieved from https://ntrs.nasa.gov/api/ citations/19990063635/downloads/19990063635.pdf

Driskell, J. E., \& Mullen, B. (2005). The efficacy of naps as a fatigue countermeasure: A meta-analytic integration. Human Factors, 47(2), 360-377. https://doi.org/10.1518/0018720054679498

Drury, D. A., Ferguson, S. A., \& Thomas, M. J. W. (2012). Restricted sleep and negative affective states in commercial pilots during short haul operations. Accident Analysis and Prevention, 45(Suppl), 80-84. https://doi.org/10.1016/j.aap.2011.09.031

Eriksen, C. A., Akerstedt, T., \& Nilsson, J. P. (2006). Fatigue in transAtlantic airline operations: diaries and actigraphy for two- vs. threepilot crews. Aviation Space and Environmental Medicine, 77(6), 605-612. Retrieved from https://tinyurl.com/yzl9dhpd

European Aviation Safety Agency. (2009). Notice of Proposed Amendment (NPA) No. 2009-02c, January30, 2009. Retrieved from https://www.easa.europa.eu/sites/default/files/dfu/NPA\%202009-02C. pdf

Federal Aviation Administration. (2013). Fatigue Risk Management Systems. Advisory Circular dated: 5/6/13. AC No: 120-103A for Aviation Safety. Retrieved from https://www.faa.gov/documentlibrary/ media/advisory_circular/ac_120-103a.pdf

Flight Safety Foundation. (2005). Lessons from the dawn of ultra-long range flight. Flight Safety Digest, Aug-Sept, 1-64. Retrieved from https://www.flightsafety.org/fsd/fsd_aug-sept05.pdf

Flynn-Evans, E. E., Ahmed, O., Berneking, M., Collen, J. F., Kancherla, B. S., Peters, B. R., Rishi, M. A., Sullivan, S. S., Upender, R., \& Gurubhagavatula, I. (2019). Industrial regulation of fatigue: Lessons learned from aviation. Journal of Clinical Sleep Medicine, 15(4), 537-538. https://doi.org/10.5664/jcsm.7704

Fourie, C., Holmes, A., Bourgeois-Bougrine, S., Hilditch, C., \& Jackson, P. (2010). A review of fatigue risk management systems. Road Safety Research Report no. 110. London, UK: Department of Transport. Retrieved from http://www.clockworkresearch.com/wp-content/ uploads/2017/10/FRMS_Literature _Review_RSRR110.pdf

Gander, P. H., Graeber, R. C., Foushee, H. C., Lauber, J. K., \& Connel, L. J. (1994). Crew factors in flight operations: II. Psychophysiological responses to short-haul air transport operations. Technical Memorandum 108856. Moffett Field, CA: NASA-Ames Research Center. Retrieved from https://rosap.ntl.bts.gov/view/dot/12819

Gillberg, M. (1984). The effects of two alternative timings of a one-hour nap on early morning performance. Biological Psychology, 19(1), 45-54. https://doi.org/10.1016/0301-0511(84)90009-7

Gillberg, M. (1995). Sleepiness and its relation to the length, content, and continuity of sleep. Journal of Sleep Research, 4(S2), 37-40. https:// doi.org/10.1111/j.1365-2869.1995.tb00224.x

Gregory, K. B., Winn, W., Johnson, K., \& Rosekind, M. R. (2010). Pilot fatigue survey: Exploring fatigue factors in air medical operations. 
Air Medical Journal, 29(6), 309-316. https://doi.org/10.1016/j.amj. 2010.07.002

Goldsmith, C. (1998). More carriers sanction their pilots' cockpit snoozes. The Wall Street Journal, January 21, 1998, B1. Retrieved from https:// search-proquest-com.ezproxy.libproxy.db.erau.edu/docview/ 398760096?pq-origsite $=$ summon

Goode, J.H. (2003). Are pilots at risk of accidents due to fatigue? Journal of Safety Research, 34(3), 309-313. https://doi.org/10.1016/s00224375(03)00033-1

Hardaway, C. A., \& Gregory, K. B. (2005). Fatigue and sleep debt in an operational navy squadron. International Journal of Aviation Psychology, 15(2), 157-171. https://doi.org/10.1207/s15327108ijap 1502_3

Hart, G. S., \& Staveland, L. E. (1988). Development of NASA-TLX (Task Load Index): Results of empirical and theoretical research. Advances in Psychology, 52, 139-183. https://doi.org/10.1016/S01664115(08)62386-9

Haugh, L., Skogstad, A., \& Hellesoy, O. H. (1994). Health, sleep and mood perceptions reported by airline crews flying short and long hauls. Aviation Space, and Environmental Medicine, 65(1), 27-34. Retrieved from https://tinyurl.com/yegkgkff

Holmes, A., Al-Bayat, S., Hilditch, C., \& Bourgeois-Bougrine, S. (2012). Sleep and sleepiness during an ultra long-range flight operation between the Middle East and United States. Accident Analysis and Prevention, 45S, 27-31. https://doi.org/10.1016/j.aap.2011.09.021

Homan, M. (2013). The use of optical waveguides in head up display (HUD) applications. Proceedings of SPIE, 8736, 87360E. https://doi. org/10.1117/12.2014513

Honn, K. A., Satterfield, P., McCauley, P., Caldwell, J. L., \& Van Dongen, H. P. A. (2016). Fatiguing effect of multiple take-offs and landings in regional airline operations. Accident Analysis and Prevention, 86, 199-208. https://doi.org/10.1016/j.aap.2015.10.005

International Civil Aviation Organization. (2012). Fatigue Risk Management Systems-Manual for Regulators. Doc. 9966.1-1. Retrieved from https://www.icao.int/safety/fatiguemanagement/frms\%20tools/ doc\%209966.frms.2011\%20edition.en.pdf

Karen, R. A. (2010). Fatigue management tools: SMS, FRMS and SAFE. Paper presented at SAFE Europe, March 30, 2010. Retrieved from https://www.safeeurope.co.uk/media/1048/karen-robertsonpresentation.pdf

Kirkland, G. (2008, June). Crewmember flight, duty and rest requirements: FAA regulations, initiatives, and challenges. Presented at the FAA Fatigue Management Symposium: Partnerships for Solutions, Vienna, VA, June. 17-19, 2008. Retrieved from http://www.anpac.it/ARC_ DOC/PUB/Documenti/Area\%20Pubblica/OLDs/TECH_old/Pilot\% 20Fatigue-FTL/Letteratura/2008-FAA-Aviation\%20Fatigue\% 20Management.pdf

Learmont, D. (2009). Proof that fatigue kills. Paper presented at FRMS Forum, QinetiQ, Farnborough, May 8, 2009. Retrieved from https:// www.eurocockpit.be/sites/default/files/Fatigue_Kills_Proof_D_ Learmount_SP_09_0528.pdf

Leproult, R., Copinschi, G., Buxton, O., \& Van Cauter, E. (1997). Sleep loss results in an elevation of cortisol levels the next evening. Sleep, 20(10), 865-870.

Luna, T. (2003). Fatigue in context: USAF mishap experience [Abstract]. Aviation Space, \& Environmental Medicine, 74(4), 388.

Lyman, E. G., \& Orlady, H. W. (1981). Fatigue and associated performance decrements in air transport operations. CR 166167. Houston, TX: NASA. Retrieved from https://ntrs.nasa.gov/citations/19810 014163

Meerlo, P., Sgoifo, A., \& Suchecki, D. (2008). Restricted and disrupted sleep: effects on autonomic function, neuroendocrine stress systems and stress responsivity. Sleep Medicine Reviews, 12(3), 197-210. https://doi.org/10.1016/j.smrv.2007.07.007

Melfi, M. L., \& Miller, J. C. (2006). Causes and effects of fatigue in experienced military aircrew and the countermeasures needed to improve flight safety. Report no. AFRL-HE-BR-TR-2006-0071. Brooks City-Base, TX: Air Force Research Laboratory. https://www. researchgate.net/publication/235048666_Causes_and_Effects_of_ Fatigue_in_Experienced_Military_Aircrew

Ministry of Civil Aviation. (2010). Report on Accident to Air India Express Boeing 737-800 Aircraft VT-AXV on 22nd May 2010 at Mangalore. Retrieved from https://www.skybrary.aero/bookshelf/ books/1680.pdf

Mohler, S. R. (1966). Clinical problems in aviation medicine: Fatigue in aviation activities. Aerospace Medicine, 37(7), 722-732. Retrieved from https://tinyurl.com/yz5y5e9x

Morin, A. K. (2006). Strategies for treating chronic insomnia. American Journal of Managed Care, 12 (8 Suppl), 230-246. Retrieved from https://tinyurl.com/yfwcrwuw

National Transportation Safety Board. (2008). The evolution of NTSB fatigue related recommendations. Presentation by Dr J M Price to FAA Fatigue Management Symposium: Partnership for Solutions, Vienna, VA.

National Transportation Safety Board. (2014). Crash of Asiana Flight 214 accident report summary. Retrieved from https://reports.aviationsafety.net/2013/20130706-0_B772_HL7742.pdf

National Transportation Safety Board. (2016). Reduce fatigue-related accidents. Retrieved from https://www.ntsb.gov/safety/mwl/Pages/ mwl1-2016.aspx

Neri, D. F. (2005). Scientific and operational issues associated with ultralong range flight. Aviation Space and Environmental Medicine, 76(3), 247-248.

Neri, D. F., Oyung, R. L., Colletti, L. M., Mallis, M. M., Tam, P. Y., \& Dinges, D. F. (2002). Controlled breaks as a fatigue countermeasure on the flight deck. Aviation, Space, and Environmental Medicine, 73(7), 654-664. Retrieved from https://tinyurl.com/ygzzqueq

Neumann, M., \& Jacobs, K. W. (1992). Relationship between dietary components and aspects of sleep. Perceptual and Motor Skills, 75(3 Pt1), 873-874. https://doi.org/10.2466/pms.1992.75.3.873

Nicholson, A. N., Pascoe, P. A., \& Spencer, M. B. (1986a). Nocturnal sleep and daytime alertness of aircrew after trans-meridian flights. Aviation Space and Environmental Medicine, 57(12 Suppl.), B43-B52.

Nicholson, A. N., Pascoe, P. A., Spencer, M. B., Stone, B. M., Roehrs, T. A., \& Roth, T. (1986b). Sleep after transmeridian flights. Lancet, 2(8517), 1205-1208. https://doi.org/10.1016/s0140-6736(86)92207-5

Noy, Y. I., Horrey, W. J., Popkin, S. M., Folkard, S., Howarth, H. D., \& Courtney, T. K. (2011). Future directions in fatigue and safety research. Accident Analysis and Prevention, 43(2), 495-497. https://doi.org/ 10.1016/j.aap.2009.12.017

Petrie, K. J., Powell, D., \& Broadbent, E. (2004). Fatigue self-management strategies and reported fatigue in international pilots. Ergonomics, 47(5), 461-468. https://doi.org/10.1080/0014013031000085653

Petrilli, R. M., Roach, G. D., Dawson, D., \& Lamond, N. (2006). The sleep, subjective fatigue, and sustained attention of commercial airline pilots during an international pattern. Chronobiology International, 23(6), 1357-1362. https://doi.org/10.1080/07420520601085925

Powell, D. M. C., Spencer, M. B., Holland, D., Broadbent, E., \& PetrieK. J. (2007). Pilot fatigue in short-haul operations: Effects of number of sectors, duty length, and time of day. Aviation Space and Environmental Medicine, 78(7), 698-701. Retrieved from https://tinyurl.com/ yerl2pk7

Ramsey, C. S., \& McGlohn, S. E. (1997). Zolpidem as a fatigue countermeasure. Aviation Space and Environmental Medicine, 68(10), 926-931. Retrieved from https://tinyurl.com/yg3ednvg

Reid, K. J., \& Burgess, H. J. (2005). Circadian rhythm sleep disorders. Primary Care: Clinics in Office Practice, 32(2), 449-473. https://doi. org/10.1016/j.pop.2005.02.002

Reis, C., Mestre, C., Canhão, H., Gradwell, D., \& Paiva, T. (2016). Sleep complaints and fatigue of airline pilots. Sleep Science, 9(2), 73-77. https://doi.org/10.1016/j.slsci.2016.05.003 
Reuters. (2013). U.S. blames pilot errors, fatigue for 2013 UPS plane crash in Alabama, by Eric Beech, Washington. Retrieved from https://www. reuters.com/article/usa-crash-ups/u-s-blames-pilot-errors-fatigue-for2013-ups-plane-crash-in-alabama-idINL1NORA1PN20140909

Roach, G. D., Sargent, C., Darwent, D., \& Dawson, D. (2012). Duty periods with early start times restrict the amount of sleep obtained by short-haul airline pilots. Accident Analysis and Prevention, 45(Suppl), 22-26. https://doi.org/10.1016/j.aap.2011.09.020

Rosekind, M. R., Miller, D. L., Gregory, K. B., \& Dinges, D. F. (2000). Crew factors in flight operations XII: A survey of sleep quantity and quality in on-board crew rest facilities. Report no. NASA/TM-200020961. Moffett Field, CA: NASA. Retrieved from https://www. researchgate.net/publication/24298610_Crew_Factors_in_Flight_ Operations_XII_A_Survey_of_Sleep_Quantity_and_Quality_in_OnBoard_Crew_Rest_Facilities

Sack, R. L., Auckley, D., Auger, R. R., Carskadon, M. A., Wright, K. P. Jr., Vitiello, M. V., \& Zhdanova, I. V. (2007). Circadian rhythm sleep disorders: part I, basic principles, shift work and jet lag disorders. An American Academy of Sleep Medicine review. Sleep, 30(11), 1460-1483. https://doi.org/10.1093/sleep/30.11.1460

Samel, A., Wegmann, H, M., \& Vejvoda, M. (1995). Jet lag and sleepiness in aircrew. Journal of Sleep Research, 4(S2), 30-36. https://doi.org/ 10.1111/j.1365-2869.1995.tb00223.x

Samel, A., Wegmann, H. M., \& Vejvoda, M. (1997). Aircrew fatigue in long-haul operations. Accident Analysis and Prevention, 29(4), 439-452. https://doi.org/10.1016/s0001-4575(97)00023-7

Shiota, M., Sudou, M., \& Ohshima, M. (1996). Using outdoor exercise to decrease jet lag in airline crewmembers. Aviation, Space and Environmental Medicine, 67(12), 1155-1160. Retrieved from https:// tinyurl.com/yzqaqvod

Spiegel, K., Leproult, R., \& Van Cauter, E. (1999). The impact of sleep debt on metabolic and endocrine function. The Lancet, 354(9188), 1435-1439. https://doi.org/10.1016/S0140-6736(99)01376-8

Stone, B. M., \& Turner, C. (1997). Promoting sleep in shift workers and intercontinental travelers. Chronobiology International, 14(2), 133-143. https://doi.org/10.3109/07420529709001151

Transport Canada. (2007). Fatigue management strategies for employees, FRMS Toolbox Document, TP14573E, April 2007. Retrieved from https://tc.canada.ca/sites/default/files/migrated/tp14573e.pdf

Transportation Safety Board of Canada. (2011). Aviation Investigation Report A11F0012. Retrieved from http://www.bst-tsb.gc.ca/eng/ rapports-reports/aviation/2011/a11f0012/A11F0012.pdf
Van Dongen, H. P., \& Dinges, D. F. (2005). Sleep, circadian rhythms, and psychomotor vigilance. Clinics in Sports Medicine, 24(2), 237-249 (vii-viii). https://doi.org/10.1016/j.csm.2004.12.007

Venkatraman, V., Chuah, Y. M. L., Huettel, S. A., \& Chee, M. W. L. (2007). Sleep deprivation elevates expectation of gains and attenuates response to losses following risky decisions. Sleep, 30(5), 603-609. Retrieved from https://doi.org/10.1093/sleep/30.5.603

Virgin Atlantic Airways. (2008). Safety Management System (SMS). Operations Manual Part A. General, Rev 24, p. 11.10.4.1.

Wehr, T. A., Moul, D. E., Barbato, G., Giesen, H. A., Seidel, J. A., \& Barker, C. (1993). Conservation of photoperiod-responsive mechanisms in humans. American Journal of Physiology, 265(4 Pt 2), 846-857. https://doi.org/10.1152/ajpregu.1993.265.4.R846

Wells, A. S., Read, N. W., Uvnas-Moberg, K., \& Alster, P. (1997). Influences of fat and carbohydrate on postprandial sleepiness, mood, and hormones. Physiology and Behavior, 61(5), 679-686. https://doi. org/10.1016/s0031-9384(96)00519-7

Williamson, A., Lombardi, D. A., Folkard, S., Stutts, J., Courtney, T. K. \& Connor, J. L. (2011). The link between fatigue and safety. Accident Analysis and Prevention, 43(2), 498-515. https://doi.org/10.1016/j.aap. 2009.11.011

Wright, N., \& McGown, A. (2001). Vigilance on the civil flight deck: Incidence of sleepiness and sleep during long-haul flights and associated changes in physiological parameters. Ergonomics, 44(1), 82-106. https://doi.org/10.1080/00140130150203893

www.skybrary.aero. (2017). Fatigue risk management system (FRMS). Retrieved from http://www.skybrary.aero/index.php/Fatigue_Risk_ Management_System(FRMS).

Yen, J.-R., Hsu, C.-C., Ho, H., Lin, F.-F., \& Yu, S.-H. (2005). Identifying flight fatigue factors: An econometric modeling approach. Journal of Air Transport Management, 11(6), 408-416. https://doi.org/10.1016/ j.jairtraman.2005.05.006

Yen, J.-R., Hsu, C.-C., Yang, H., \& Ho, H. (2009). An investigation of fatigue issues on different flight operations. Journal of Air Transport Management, 15(5), 236-240. https://doi.org/10.1016/j.jairtraman. 2009.01.001

Yıldız, B. C., Gzara, F., \& Elhedhli, S. (2017). Airline crew pairing with fatigue: modelling and analysis. Transport Research Part C Emerging Technologies, 74, 99-112. https://doi.org/10.1016/j.trc.2016.11.002

Zammit, G. K., Kolevzon, A., Fauci, M., Shindledecker, R., \& Ackerman, S. (1995). Postprandial sleep in healthy men. Sleep, 18(4), 229-231. https://doi.org/10.1093/sleep/18.4.229. 